\title{
Allergic contact dermatitis and changes in the frequency of the causative allergens demonstrated with patch testing in 2008-2012
}

\author{
Martin Tichy, Iva Karlova
}

Background. The frequency of contact allergens is often regionally different and hence it regional identification is important for the prevention of allergic contact dermatitis (ACD).

Objectives. The aim of the study was to determine the most common contact allergens in the etiology of ACD from 2008-2012 and evaluate their dynamics in comparison with similar studies in the Czech Republic and internationally carried out in previous years.

Methods. A total of 1941 patients with suspected ACD were examined using the patch tests from the European Standard Series. The data obtained were subjected to statistical analysis.

Results. The most common contact allergy was to nickel (15.4\%), the second most frequent allergen was Balsam of Peru (11.6\%). The top five allergens in the whole sample also included, in descending order, fragrance-mix I (7.1\%), cobalt chloride (6.4\%), and Kathon CG (4.0\%). While the order of contact allergens causing sensitisation in women is consistent with the results of the whole sample, in men instead of cobalt and Kathon CG, epoxy resin and chromium appeared among the five most common allergens.

Conclusions. In the Czech Republic, despite existing EU legislation, action to reduce the frequency of sensitization to nickel failed in contrast to other EU countries. In addition to nickel, consistent preventive measures should be focused mainly on sensitization to Balsam of Peru, cobalt, epoxy resins, chromium and aromatic substances and preservatives used in the cosmetic industry.

Key words: balsam of peru, chromium, cobalt, contact dermatitis, epoxy resin, fragrance-mix I, Kathon CG, nickel, patch tests

Received: December 11, 2013; Accepted with revision: April 16, 2014; Available online: May 30, 2014 http://dx.doi.org/10.5507/bp.2014.022

Department of Dermatology and Venereology, Faculty of Medicine and Dentistry, Palacky University Olomouc and University Hospital Olomouc, Czech Republic

Corresponding author: Martin Tichy, e-mail: tichy.martin.jun@fnol.cz

\section{INTRODUCTION}

Allergic contact dermatitis (ACD) is defined as a noninfectious inflammatory disease of the skin, with delayed type of hypersensitivity reactions playing a crucial role in its ethiopathogenesis ${ }^{1}$. It is one of the most common skin diseases, and often significantly limits normal activity or work.

Patch tests (PT) are crucial in the diagnosis of ACD. The principle of PT is controlled exposure of the patient to the suspected substance to cause ACD in the tested area.

Most frequently occurring contact allergens are part of the so-called standard patch test sets. Europe uses the European Standard Series, which currently comprises 28 of the most common allergens, and a control. Results from extensive studies clearly show that, despite a slightly downward trend, the most common contact allergen is nickel, while positivity for other allergens in the PT and their causal relationship with ACD often varies regionally. Revealing the most frequent allergens in the monitored area can contribute to the implementation of preventive measures and result in reduction in the incidence of ACD.
A recent extensive study on detection of the most common contact allergens in the Czech population was carried out and published in 2005 (ref. ${ }^{1}$ ). Our aim was to assess any changes in the frequency of the contact allergens involved in the ACD etiology in the Czech population and define their potential causes.

\section{METHODS}

Between 2008 and 2012, a total of 1,941 patients who were considered clinically suspect of allergic contact dermatitis underwent patch tests at the Department of Dermatology and Venereology, University Hospital in Olomouc. The cohort of patients was sufficiently representative not only in terms of the number and age, but also in terms of the structure of the population tested. Patients were from different areas to avoid sample bias e.g. by a specific industrial production.

The European Standard Series Chemotechnique was used, which includes 28 of the most common allergens and a control. For adhesion, we used Curatest (Lohmann and Rauscher) test patches. 
The tests were applied to intact skin on the upper half of the back. Patients were not tested during the acute phase of the disease, and did not take antihistamines or immunosuppressants.

PTs were retained on the skin for 48 hours and repeatedly read after removal on the second day (D2), third (D3) and fourth (D4) days. In the subsequent analysis, the degree of allergic reaction positivity was taken into account. The data were statistically analysed using the chi-square and the Fisher's exact tests.

\section{RESULTS}

The tests were conducted in a total of 1941 patients, of whom 1353 (69.7\%) were women and 588 (30.3\%) men. The mean age was 40.8 years; the youngest patient was five years old, and the oldest 83 years old.

Dermatitis was most often located on the hands ( $46 \%$ of cases). The second most common site of dermatitis was the face and neck (21\%), while the remaining patients were affected in other areas (15\%). Contact hypersensitivity was detected in 859 (44.2\%) patients. 501 patients $(25.8 \%)$ were diagnosed with hypersensitivity to one allergen, and 358 patients (18.4\%) with hypersensitivity to two or more allergens. The following table shows the fre-

Table 1. Documented contact allergens in 2008-2012, in total.

\begin{tabular}{|c|c|c|c|c|c|c|c|}
\hline $\begin{array}{l}\text { Sequence } \\
\text { number }\end{array}$ & Allergen & $\begin{array}{c}\text { Number of } \\
\text { positive find- } \\
\text { ings }\end{array}$ & $\%$ & M & $\%$ & $\mathrm{~W}$ & $\%$ \\
\hline 1 & Potassium dichromate $(0.5$, pet. $)$ & 76 & $3.9 \%$ & 28 & $4.8 \%$ & 48 & $3.5 \%$ \\
\hline 2 & Neomycin sulphate (20, pet.) & 28 & $1.4 \%$ & 5 & $0.9 \%$ & 23 & $1.7 \%$ \\
\hline 3 & Thiuram-mix (1, pet.) & 40 & $2.1 \%$ & 10 & $1.7 \%$ & 30 & $2.2 \%$ \\
\hline 4 & Paraphenylendiamin (PPD) (1, pet.) & 53 & $2.7 \%$ & 10 & $1.7 \%$ & 43 & $3.2 \%$ \\
\hline 5 & Cobalt chloride (1, pet.) & 124 & $6.4 \%$ & 21 & $3.6 \%$ & 103 & $7.6 \%$ \\
\hline 6 & Benzocain (5, pet.) & 10 & $0.5 \%$ & 1 & $0.2 \%$ & 9 & $0.7 \%$ \\
\hline 7 & Formaldehyde (1, aq.) & 17 & $0.9 \%$ & 6 & $1.0 \%$ & 11 & $0.8 \%$ \\
\hline 8 & Colophonium (20, pet.) & 56 & $2.9 \%$ & 18 & $3.1 \%$ & 38 & $2.8 \%$ \\
\hline 9 & Clioquinol ( 5 , pet.) & 13 & $0.7 \%$ & 4 & $0.7 \%$ & 9 & $0.7 \%$ \\
\hline 10 & Balsam of Peru (25, pet.) & 225 & $11.6 \%$ & 70 & $11.9 \%$ & 155 & $11.5 \%$ \\
\hline 11 & $\begin{array}{l}\text { N-Isopropyl - } \mathrm{N} \text { - phenyl para-phenylenedi- } \\
\text { amine }(0.1 \text {, pet.) }\end{array}$ & 11 & $0.6 \%$ & 1 & $0.2 \%$ & 10 & $0.7 \%$ \\
\hline 12 & Lanolin alcohol (30, pet.) & 51 & $2.6 \%$ & 8 & $1.4 \%$ & 43 & $3.2 \%$ \\
\hline 13 & Mercapto-mix (1, pet.) & 4 & $0.2 \%$ & 2 & $0.3 \%$ & 2 & $0.1 \%$ \\
\hline 14 & Epoxy resin (1, pet.) & 57 & $2.9 \%$ & 45 & $7.7 \%$ & 12 & $0.9 \%$ \\
\hline 15 & Paraben-mix (16, pet.) & 20 & $1.0 \%$ & 6 & $1.0 \%$ & 14 & $1.0 \%$ \\
\hline 16 & $\begin{array}{l}\text { Paratertiarybutyl phenol-formaldehyde resin } \\
\text { (1, pet.) }\end{array}$ & 4 & $0.2 \%$ & 0 & $0.0 \%$ & 4 & $0.3 \%$ \\
\hline 17 & Fragrance-mix I (8, pet.) & 137 & $7.1 \%$ & 33 & $5.6 \%$ & 104 & $7.7 \%$ \\
\hline 18 & Quaternium-15 (1, pet.) & 13 & $0.7 \%$ & 3 & $0.5 \%$ & 10 & $0.7 \%$ \\
\hline 19 & Nickel sulphate $(5$, pet. $)$ & 298 & $15.4 \%$ & 35 & $6.0 \%$ & 263 & $19.4 \%$ \\
\hline 20 & Kathon CG (0.01, aq.) & 78 & $4.0 \%$ & 21 & $3.6 \%$ & 57 & $4.2 \%$ \\
\hline 21 & Mercaptobenzothiazole (2, pet.) & 6 & $0.3 \%$ & 2 & $0.3 \%$ & 4 & $0.3 \%$ \\
\hline 22 & Sesquiterpene lactone-mix (0.1, pet.) & 10 & $0.5 \%$ & 1 & $0.2 \%$ & 9 & $0.7 \%$ \\
\hline 23 & Primin $(0.01$, pet. $)$ & 6 & $0.3 \%$ & 2 & $0.3 \%$ & 4 & $0.3 \%$ \\
\hline 24 & Budesonide (0.01, pet.) & 34 & $1.8 \%$ & 16 & $2.7 \%$ & 18 & $1.3 \%$ \\
\hline 25 & Tixocortol-21-pivalate (0.1, pet.) & 22 & $1.1 \%$ & 6 & $1.0 \%$ & 16 & $1.2 \%$ \\
\hline 26 & Dibromodicyanobutane (0.5, pet.) & 15 & $0.8 \%$ & 5 & $0.9 \%$ & 10 & $0.7 \%$ \\
\hline 27 & Fragrance-mix II (14, pet.) & 40 & $2.1 \%$ & 13 & $2.2 \%$ & 27 & $2.0 \%$ \\
\hline \multirow[t]{3}{*}{28} & Lyral $(5$, pet. $)$ & 32 & $1.6 \%$ & 3 & $0.5 \%$ & 29 & $2.1 \%$ \\
\hline & & $\begin{array}{c}\text { Number of } \\
\text { tested }\end{array}$ & $\%$ & M & $\%$ & $\mathrm{~W}$ & $\%$ \\
\hline & Total & 1,941 & $100.0 \%$ & 588 & $30.3 \%$ & 1,353 & $69.7 \%$ \\
\hline
\end{tabular}

M - men, W - women, Aq.- aqua, Pet.- petrolatum 
Table 2. Men vs. women - comparison of positive reactions to the selected allergens, total for 2008-2012.

\begin{tabular}{clcrrrrrr}
\hline $\begin{array}{c}\text { Sequence } \\
\text { number }\end{array}$ & \multicolumn{1}{c}{ Allergen } & $\begin{array}{c}\text { Number of } \\
\text { positives }\end{array}$ & $\%$ & M & \% & W & \% & $\begin{array}{c}\text { M vs. W } \\
P\end{array}$ \\
\hline 1 & Potassium dichromate & 76 & $3.9 \%$ & 28 & $4.8 \%$ & 48 & $3.5 \%$ & 0.205 \\
5 & Cobalt chloride & 124 & $6.4 \%$ & 21 & $\mathbf{3 . 6} \%$ & 103 & $\mathbf{7 . 6 \%}$ & $\mathbf{0 . 0 0 1}$ \\
10 & Balsam of Peru & 225 & $11.6 \%$ & 70 & $11.9 \%$ & 155 & $11.5 \%$ & 0.777 \\
14 & Epoxy resin & 57 & $2.9 \%$ & 45 & $\mathbf{7 . 7} \%$ & 12 & $\mathbf{0 . 9} \%$ & $\mathbf{< 0 . 0 0 0 1}$ \\
17 & Fragrance-mix I & 137 & $7.1 \%$ & 33 & $5.6 \%$ & 104 & $7.7 \%$ & 0.101 \\
19 & Nickel sulphate & 298 & $15.4 \%$ & 35 & $\mathbf{6 . 0} \%$ & 263 & $\mathbf{1 9 . 4 \%}$ & $<\mathbf{0 . 0 0 0 1}$ \\
20 & Kathon CG & 78 & $4.0 \%$ & 21 & $3.6 \%$ & 57 & $4.2 \%$ & 0.508 \\
\hline
\end{tabular}

$P$... significance of the chi-square test

quency of positive reactions to the allergens tested in the basic set during the studied period (Table 1). Bold marks the five allergens which were the most common cause of contact allergy in the whole group, and two allergens (epoxy resin and potassium dichromate) that were among the five most common in the male-only set.

Nickel was determined to be the most common contact allergen (15.4\%), the second most frequent allergen was Balsam of Peru (11.6\%). The top five allergens in the whole sample also included, in descending order, fragrance-mix I (7.1\%), cobalt chloride (6.4\%), and Kathon CG $(4.0 \%)$.

Differences were noted in the etiology of the contact sensitivity in men and women. In the women, the most often determined allergen was nickel (19.4\%), with the other four most common being Balsam of Peru (11.5\%), fragrance-mix I (7.7\%), cobalt (7.6\%), and Kathon CG $(4.2 \%)$.

In men, the most frequent positive reactions were to Balsam of Peru (11.9\%), followed by epoxy resin (7.7\%). Most men (64\%) were sensitised to epoxy resin at work. Surprisingly, the third most common allergen in men was nickel (6\%), followed by fragrance-mix I (5.6\%), and chromium $(4.8 \%)$.

Less than $0.5 \%$ of positive reactions were found in the following allergens: mercapto mix, mercaptobenzothiazole, 4-tert Butyl phenoformaldehyde resin (ptBFF), and primine.

Statistically significant differences in the incidence of the positive reactions in men and women in the case of the seven most common allergens are shown in Table 2.
A significantly higher incidence of positive reactions in women was shown to cobalt chloride (W vs. M: $7.6 \%$ vs. $3.6 \%, P=0.001$ ) and nickel sulphate (W vs. M: $19.4 \%$ vs. $6.0 \%, P<0.0001)$. Conversely, in the epoxy resin, a significantly higher incidence of positive reactions occurred in men ( $\mathrm{M}$ vs. W: $7.7 \%$ vs. $0.9 \%, P<0.0001$ ). For potassium dichromate, Balsam of Peru, fragrance-mix I, and Kathon $\mathrm{CG}$, the differences between men and women were not statistically significant.

In 2008-2012 were reported 625 cases of occupational $A C D$ via the health system of Czech republic. In the studied set, occupational ACD was diagnosed in 108 patients in the same period (5.6\% of ACD in the studied set and $17.3 \%$ of all occupational ACD reported in the Czech Republic), of whom 70 were men (12\%) and 38 women (3\%).

The most important occupational allergen in men was epoxy resin, which was the cause of ACD in 29 patients $(41.4 \%)$. In individually studied years, men were diagnosed in $40-63 \%$ of all the reported occupational ACD cases (Table 3). The most common source of sensitisation was epoxy resins contained in paints, varnishes and adhesives. In women, hypersensitivity to contact epoxy resin as the cause of occupational ACD during the study period was diagnosed in only four cases.

The most common occupational allergen in women was thiuram-mix, which caused ACD in nine cases $(24 \%$ of all occupational ACD cases in women). The source of sensitisation in most cases was protective rubber gloves.

Comparison of the incidence of contact allergy caused by the seven studied, and most common, allergens in each year and evaluation of the statistically significant differences are shown in the following tables (Table 4, 5, 6, 7).

Table 3. Occupational contact allergic dermatitis in men (2008-2012).

\begin{tabular}{lccccc}
\hline & 2008 & 2009 & 2010 & 2011 & 2012 \\
\hline ACD in total & 19 & 9 & 15 & 10 & 7 \\
Occupational ACD to epoxy resin & 12 & 4 & 6 & 4 & 3 \\
Occupational ACD to epoxy resin $\%$ & $63 \%$ & $44 \%$ & $40 \%$ & $40 \%$ & $43 \%$ \\
\hline
\end{tabular}


Table 4. Comparison of the incidence in individual years, $\mathrm{M}+\mathrm{W}$ total.

\begin{tabular}{lccccccc}
\hline & $\begin{array}{c}2008 \\
\mathrm{n}=337\end{array}$ & $\begin{array}{c}2009 \\
\mathrm{n}=376\end{array}$ & $\begin{array}{c}2010 \\
\mathrm{n}=474\end{array}$ & $\begin{array}{c}2011 \\
\mathrm{n}=382\end{array}$ & $\begin{array}{c}2012 \\
\mathrm{n}=372\end{array}$ & $P^{\mathrm{a}}$ & $P^{\mathrm{b}}$ \\
\hline Potassium dichromate & 3.6 & 5.6 & 3.2 & 4.5 & 3.0 & 0.308 & 0.677 \\
Cobalt chloride & 6.8 & 6.9 & 6.1 & 7.1 & 5.1 & 0.799 & 0.344 \\
Balsam of Peru & 11.9 & 12.8 & 11.4 & 12.6 & 9.4 & 0.621 & 0.328 \\
Epoxy resin & 5.0 & 2.4 & 3.0 & 2.1 & 2.7 & 0.162 & 0.118 \\
Fragrance-mix I & 7.1 & 5.6 & 8.4 & 8.1 & 5.6 & 0.354 & 0.444 \\
Nickel sulphate & 13.9 & 16.2 & 12.7 & 15.4 & 19.1 & 0.117 & 0.070 \\
Kathon CG & 2.1 & 3.5 & 4.0 & 5.2 & 5.1 & 0.184 & $\mathbf{0 . 0 3 2}$ \\
\hline
\end{tabular}

a ... level of significance of the chi-square test for comparison 2008 vs. 2009 vs. 2010 vs. 2011

b ... level of significance of the chi-square test for comparison 2008 vs. 2012

n... number of tested

Table 5. Comparison of the incidence in individual years, men.

\begin{tabular}{lccccccc}
\hline & $\begin{array}{c}2008 \\
\mathrm{n}=115\end{array}$ & $\begin{array}{c}2009 \\
\mathrm{n}=122\end{array}$ & $\begin{array}{c}2010 \\
\mathrm{n}=149\end{array}$ & $\begin{array}{c}2011 \\
\mathrm{n}=102\end{array}$ & $\begin{array}{c}2012 \\
\mathrm{n}=100\end{array}$ & $P^{\mathrm{a}}$ & $P^{\mathrm{b}}$ \\
\hline Potassium dichromate & 6.1 & 7.4 & 2.7 & 4.9 & 3.0 & 0.356 & 0.344 \\
Cobalt chloride & 5.2 & 4.9 & 2.0 & 5.9 & 0 & 0.051 & $\mathbf{0 . 0 3 1}$ \\
Balsam of Peru & 12.2 & 13.1 & 12.8 & 11.8 & 9.0 & 0.898 & 0.512 \\
Epoxy resin & 12.2 & 6.6 & 7.4 & 4.9 & 7.0 & 0.373 & 0.252 \\
Fragrance-mix I & 4.3 & 2.5 & 10.7 & 2.9 & 6.0 & $\mathbf{0 . 0 3 5}$ & 0.785 \\
Nickel sulphate & 6.1 & 7.4 & 5.4 & 3.9 & 7.0 & 0.825 & 0.790 \\
Kathon CG & 1.7 & 0.8 & 3.4 & 7.8 & 5.0 & $\mathbf{0 . 0 4 6}$ & 0.255 \\
\hline
\end{tabular}

a ... level of significance of the chi-square test for comparison 2008 vs. 2009 vs. 2010 vs. 2011 vs. 2012

b ... level of significance of the chi-square test for comparison 2008 vs. 2012

Table 6. Comparison of the incidence by individual years, women.

\begin{tabular}{lccccccc}
\hline & $\begin{array}{c}2008 \\
\mathrm{n}=222\end{array}$ & $\begin{array}{c}2009 \\
\mathrm{n}=254\end{array}$ & $\begin{array}{c}2010 \\
\mathrm{n}=325\end{array}$ & $\begin{array}{c}2011 \\
\mathrm{n}=280\end{array}$ & $\begin{array}{c}2012 \\
\mathrm{n}=272\end{array}$ & $P^{\mathrm{a}}$ & $P^{\mathrm{b}}$ \\
\hline Potassium dichromate & 2.3 & 4.7 & 3.4 & 4.3 & 2.9 & 0.578 & 0.780 \\
Cobalt chloride & 7.7 & 7.9 & 8.0 & 7.5 & 7.0 & 0.993 & 0.862 \\
Balsam of Peru & 11.7 & 12.6 & 10.8 & 12.9 & 9.6 & 0.736 & 0.464 \\
Epoxy resin & 1.4 & 0.4 & 0.9 & 1.1 & 1.1 & 0.853 & 1.000 \\
Fragrance-mix I & 8.6 & 7.1 & 7.4 & 10.0 & 5.5 & 0.363 & 0.212 \\
Nickel sulphate & 18.0 & 20.5 & 16.0 & 19.6 & 23.5 & 0.212 & 0.150 \\
Kathon CG & 2.3 & 4.7 & 4.3 & 4.3 & 5.1 & 0.578 & 0.106 \\
\hline
\end{tabular}

a ... level of significance of the chi-square test for comparison 2008 vs. 2009 vs. 2010 vs. 2011 vs. 2012

b ... level of significance of the Fisher's exact test for comparison 2008 vs. 2012

A significantly higher incidence of positive reactions was demonstrated only for Kathon CG in 2012 compared with 2008 ( $5.1 \%$ vs. $2.1 \%, P=0.032$ ).

In 2012, a significantly lower incidence of positive reactions in cobalt chloride compared to 2008 ( $0 \%$ vs. $5.2 \%$, $P=0.031$ ) was shown.

For fragrance-mix I and Kathon CG, where the levels of significance for the entire contingency table $<0.05$, significant differences in the incidence of positive reactions in individual years were not observed when using more detailed analysis.
No significant difference in the incidence of positive reactions in individual years was demonstrated in women.

In 2010 and 2012 there was a significantly higher incidence of positive reactions with cobalt chloride in women (Year 2010: $\mathrm{W}$ vs. $\mathrm{M} 9.0 \%$ vs. $2.0 \%, P=0.012$, Year 2012: $\mathrm{W}$ vs. $\mathrm{M} 7.0 \%$ vs. $0 \%, P=0.003$ ).

In 2008-2012 there was a significantly higher incidence of positive reactions to epoxy resin in men ( $\mathrm{M}$ vs. W: Year 2008: $12.2 \%$ vs. $1.4 \%, P<0.0001$, Year 2009: 6.6\% vs. $0.4 \%, P=0.001$, Year $2010: 7.4 \%$ vs. $0.9 \%, P=0.001$, Year 2011: $4.9 \%$ vs. $1.1 \%, P<0.0001$, Year $2012: 7.0 \%$ vs. $1.1 \%$, $P=0.005$ ). 
Table 7. Comparison of the incidence in men and women for individual years.

\begin{tabular}{lccccc}
\hline & 2008 & 2009 & 2010 & 2011 & 2012 \\
\hline Potassium dichromate & 0.116 & 0.339 & 0.785 & 0.783 & 1.000 \\
Cobalt chloride & 0.498 & 0.386 & 0.012 & 0.659 & 0.003 \\
Balsam of Peru & 1.000 & 0.870 & 0.563 & 0.863 & 1.000 \\
Epoxy resin & $<0.0001$ & 0.001 & $<0.0001$ & 0.034 & 0.005 \\
Fragrance-mix I & 0.184 & 0.092 & 0.219 & 0.032 & 0.805 \\
Nickel sulphate & 0.003 & 0.001 & 0.001 & $<0.0001$ & $<0.0001$ \\
Kathon CG & 1.000 & 0.069 & 0.802 & 0.194 & 1.000 \\
\hline
\end{tabular}

The table shows the level of significance, using Fisher's exact test.

In 2011 there was a significantly higher incidence of positive reactions with fragrance-mix I in women $(10.0 \%$ vs. $2.9 \%, P=0.032$ ).

In 2008-2012 there was a significantly higher incidence of positive reactions to nickel sulphate in women ( $\mathrm{W}$ vs. M: Year 2008: $18.0 \%$ vs. $6.1 \%, P=0.003$, Year 2009: $20.5 \%$ vs. $7.4 \%, P=0.001$, Year $2010: 16.0 \%$ vs. $5.4 \%, P=0.001$, Year 2011: $19.0 \%$ vs. $3.9 \%, P<0.0001$, Year 2012: $23.5 \%$ vs. $7.0 \%, P<0.0001)$.

\section{DISCUSSION}

The five most common contact allergens in the test set included nickel, Balsam of Peru, Fragrance-mix I, cobalt chloride and Kathon CG, closely followed by sensitivity to potassium dichromate. In other allergens, the sensitisation was demonstrated in less than $3 \%$ of the patients (Table 1). Significant differences in sensitisation between men and women were found. The order of contact allergens causing sensitisation in women follows the results of the entire cohort. Significant differences in the proportion of allergens causing ACD were seen in the studied group of men compared to the women, where instead of cobalt and Kathon CG appearing among the five most common allergens, we saw epoxy resin and chrome.

Regarding the hypersensitivity to nickel, a significantly higher number of sensitised women (Table 2), not only in the five-year average but also in each of the individually studied years (Table 7) is not surprising. These data are consistent with the outcomes of other studies carried out in the Czech Republic and other European countries, and are largely the result of wearing inexpensive jewellery ${ }^{2-9}$.

A high prevalence of sensitisation to nickel since the end of the 1980s in Nordic countries was due to the introduction of preventive measures aimed to limit the release of nickel from objects in direct contact with skin. The first such measure was taken in Denmark back in 1989 and has gradually caught on in other European countries ${ }^{10,11}$. According to current EU legislation, release of nickel in products that come into direct and prolonged contact with skin must not exceed $0.5 \mu \mathrm{g} / \mathrm{cm}^{2} /$ week, and nickel release from items inserted into pierced parts of the body (not only during epithelisation after piercing) should be less than $0.2 \mu \mathrm{g} / \mathrm{cm}^{2} /$ week $^{11}$.

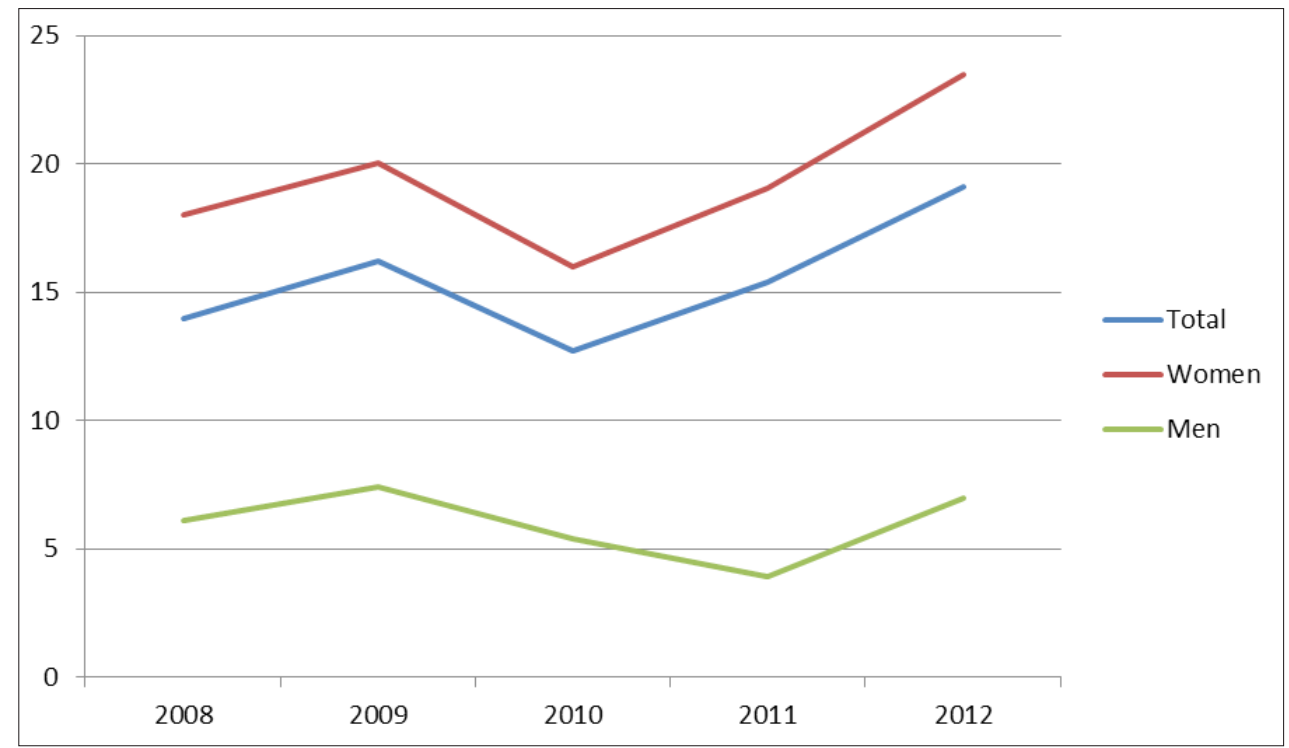

Fig. 1. The development of sensitisation to nickel in the period 2008-2012. 
According to some studies, the established preventive measures have reduced the incidence of contact allergy to nickel. For example, young Danish women (18-35 years) who had ear piercing before 1990 experienced a significantly higher prevalence of allergy to nickel than women who had piercings after 1990 (ref. ${ }^{11,12}$ ). When analysing the results of PT from 82991 patients during the years 1992 to 2001 in Germany, sensitisation decreased among women younger than 30 years from $36.7 \%$ to $25.8 \%$ (ref. ${ }^{13}$ ). In our cohort, a decreasing trend of sensitisation to nickel in the studied period was not seen, not even in the whole cohort, or in an isolated cohort of women (Fig. 1, Table 4, 5, 6). Comparing our results with a study conducted in the Czech Republic in 1997-2001 that included 12058 patients $^{2}$, there was a slight increase in the number of patients with known hypersensitivity to nickel (in total $13.8 \%$ - 15.4\%, women $19.1 \%$ - 19.4\%). In comparison with the EU countries mentioned, it is therefore clear that the Czech Republic has failed to reduce the number of patients sensitized to nickel. The causes of this condition can be seen in regionally different patients' approach to the issue (obtaining information, fashion trends - piercing, wearing cheap jewellery) and in terms of strict compliance with the above legislation, especially outside the shops.

The second most frequent contact allergen in the present study was Balsam of Peru (11.6\%), and within five years the incidence of ACD induced by Balsam of Peru ranged from 9.4 to $12.6 \%$, the differences in the individual years were not statistically significant (Table 4, 5, 6). Also, differences between men and women were minimal and not statistically significant (Table 2). The incidence of contact allergy to Balsam of Peru in the present study is clearly higher in comparison with other European studies $^{4,5}$. The difference is obvious, though not as pronounced as in comparison with the aforementioned survey conducted in the Czech Republic ${ }^{2}$. The cause of the persistent high incidence of hypersensitivity to Balsam of Peru is mainly due to regional practices in topical therapy, where it is contained in some external medicinal products for its antiseptic effect and is very popular in non-dermatological clinics for treating various types of chronic wounds. ACD around leg ulcers is most commonly caused by this allergen ${ }^{14-16}$.

The third most common allergen was a mixture of fragrant substances, fragrance-mix I (7.1\%). While consistent with the literature, the sensitisation was more common among women $(7.7 \%)$ than men (5.6\%). However, this difference is not statistically significant (Table 2).

Through fragrance-mix I, we can diagnose up to $75 \%$ of all allergies to perfumes ${ }^{2}$. Sensitisation to fragrance substances occurs most often in middle-aged women ${ }^{17}$. In some studies in recent years, a decrease in the frequency of sensitisation to fragrance-mix I was observed ${ }^{17}$, in contrast to our group, where we observed a steady trend: in the five-year interval, frequency of sensitisation to fragrance-mix I ranged from 5.6-8.4\% (Table 4).

The fourth most frequent allergen in the present study was cobalt, where a significantly higher number of affected women $(7.6 \%)$ compared to men $(3.6 \%)$ corresponds with the results of other studies (Table 2) $\left(\right.$ ref. $\left.^{2-9}\right)$. Allergy to cobalt occurs less commonly as monovalent, and more often as a combined allergy: with nickel in women and chromium in men ${ }^{9-11}$.

After the introduction of regulatory measures by the EU to replace nickel by cobalt in inexpensive jewellery, there was legitimate concern that in parallel with a reduction in the frequency of sensitization to nickel there could be a significant increase in sensitivity to cobalt. It appears that this theory was not confirmed in practice.

A large Danish study of 19335 women showed that the prevalence of contact allergy to nickel decreased after the introduction of preventive measures, and remained constant in the case of cobalt ${ }^{11}$. Virtually sustained rates of ACD to cobalt were also observed in our cohort, and in the final year of monitoring, we even recorded a slight decline (Table 4).

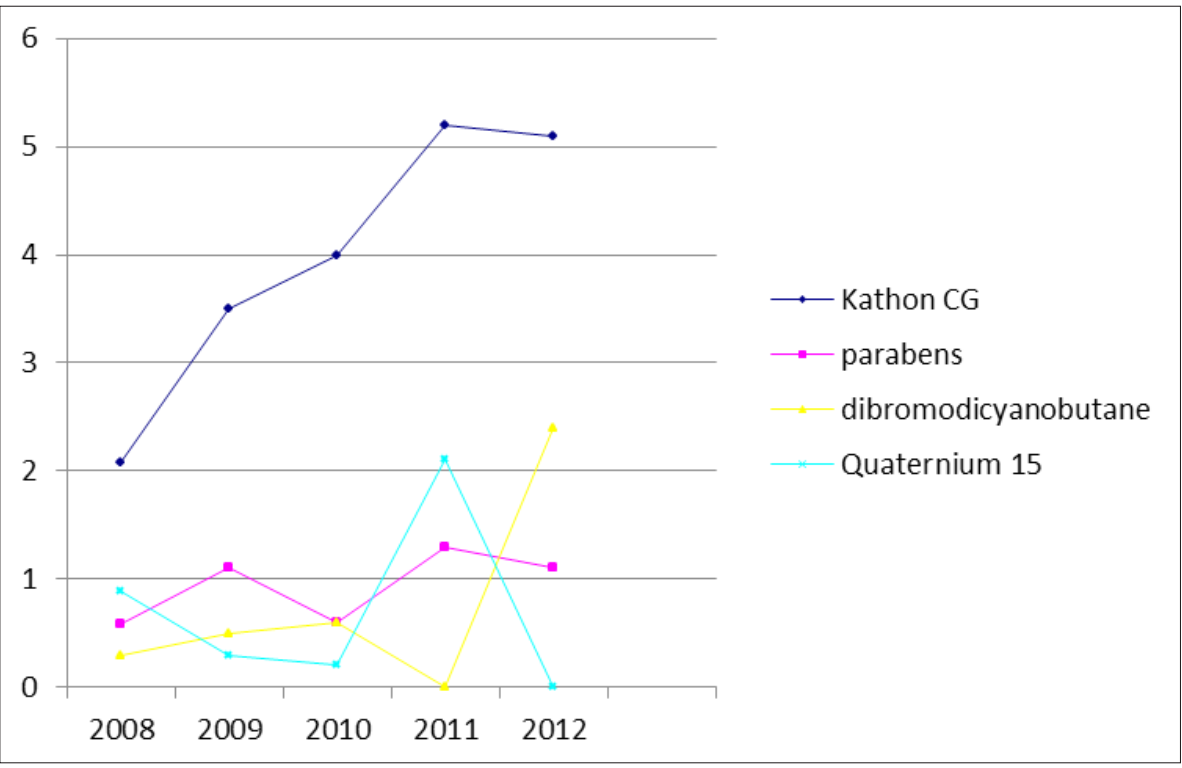

Fig. 2. The development of sensitisation to preservatives in the period 2008-2012. 
The top five allergens in the present study include Kathon CG. It is a mixture of 5-chloro-2-methyl-4-isothiazolin and 2-methyl-4-isothiazolin in a ratio 3:1. Even at low concentration, it is effective against bacteria, fungi and yeasts, and therefore is widely used, for example, in the cosmetics industry or for the preservation of industrial fluids. In the Czech Republic, in 2011 a cohort of 2944 eczema patients demonstrated hypersensitivity to Kathon $\mathrm{CG}$ in $4.1 \%$ cases $^{18}$, which is practically the same result as in our present study.

These data document a significantly increasing trend of sensitisation to Kathon CG in comparison with the extensive studies carried out in the 1990s and at the beginning of the millennium ${ }^{2,3,5,7}$. The frequency of hypersensitivity to other preservatives included in the standard set (parabens, dibromodicyanobutane, Quaternium 15) is significantly lower and ranges in our study between 0.5 $1 \%$, which is consistent with the results of prior European studies (Fig. 2) (ref. ${ }^{2-9}$ ). This may perhaps be due to the higher sensitising potential of Kathon CG in comparison with other substances with regard to its widespread use, since exposure to individual products should not be fundamentally different. The possibility of reducing the percentage of sensitised patients to Kathon $\mathrm{CG}$ is suggested in some studies that have shown a decreased sensitisation manifested as ACD when this preservative is used only in products that are rinsed off and not in products that remain on the $\operatorname{skin}^{19}$.

Another two allergens played an important role in the studied population of men: epoxy resin and chromium, which replaced Cobalt and Kathon $\mathrm{CG}$ in the group of five most common allergens (Tables 1,2).

Particularly striking, a statistically significant difference was observed in the frequency of ACD to epoxy resin in men (7.7\%) and women (0.9\%) (Table 2$)$; and in all studied years (Table 7). In men, epoxy resin was the second most common allergen, and overall, the seventh most common. Epoxy resins are widely used in industry for their strong adhesive properties, durability and strength. They are used as adhesives for rubber, metals, plastics, and are contained in hard paints and varnishes. They are also used in floor surface treatment, and in electronics, aerospace and automotive industries. Approximately $75-95 \%$ of epoxy resins are formed by polymerization of diglycidyl ether of bisphenol A, and only $1 \%$ by the polymerization of diglycidyl ether of bisphenol $\mathrm{F}\left(\right.$ ref. $\left.^{20}\right)$.

Epoxy resins are among the most common occupational allergens, and due to their use it is logical that men are more often sensitised ${ }^{20-22}$. Sensitisation occurs in people who work with uncured epoxy resin; fully cured resin does not cause sensitisation. A high percentage of occupational ACD to epoxy resin significantly contributes to the total number of sensitised patients even in our group. Of a total of 45 men allergic to epoxides, 29 (64\%) were sensitised because of their jobs (Table 3). Most often they worked as painters who used epoxy coatings, and construction workers.

Contact allergy may arise not only through epoxy resins, but also from the curing agent and diluents added to the epoxy systems ${ }^{20}$. This type of hypersensitivity is another common cause of occupational ACD. Clinical manifestations of ACD to epoxy resin are most often seen on the hands and forearms, but it is not exceptional for the face to be affected through airborne exposure ${ }^{20,22,23}$.

Given that epoxy resins are increasingly used materials, the literature reflects the increasing incidence of cases of ACD by epoxy resins. The importance of preventive measures in the form of consistent education of workers about occupational hygiene, to avoid contamination of the skin with epoxides and wearing adequate protective gear is increasing ${ }^{20}$. Further development will show whether prevention will be effective.

In the present study, chromium was also among the top five allergens in men. Hypersensitivity to potassium dichromate has been shown in $3.9 \%$ of all patients: $4.8 \%$ in men and $3.5 \%$ in women. Higher frequencies of ACD caused by chromium in the male population are common, although the difference in the incidence of hypersensitivity to chromium in men and women was not statistically significant. Men are often sensitised by contact with hexavalent chromium contained in cement ${ }^{2,9,24}$. To reduce the risk of sensitisation, regulatory measures were adopted by which ferrous sulphate is added to cement to reduce the content of hexavalent chromium. The EU regulation limiting the content of chromium in cement has been in force since January 2005 (ref. $^{2,24}$ ). According to some studies, positive results of these measures to reduce the incidence of contact allergy to chromium in workers in construction have been noted ${ }^{9,24}$.

\section{CONCLUSION}

The proportion of individual allergens in the European Standard Series in the etiology of ACD within EU countries is, in the long term, rather similar, although some differences and changes over time can be identified based on the results of extensive studies. In our study consisting of a sufficiently large group of patients, we aimed to capture the proportion of individual allergens from the European Standard Series causing ACD in recent years, and to compare the results not only with the results of previous studies concerning the frequency of contact allergens in the Czech population in 1995-2005, but also with the results of studies conducted in other EU countries. In comparison with other countries the rising frequency of hypersensitivity to nickel is slightly disturbing. Although nickel is generally known as a strong sensitizer and remains the most common contact allergen, in some countries the number of sensitized patients was significantly reduced through consistent compliance with legislative measures and proper awareness.

It was found that the trend in the Czech Republic is the opposite, and it will be necessary to consistently educate patients about the risks of wearing cheap jewellery containing nickel, especially in situations where the trader is not able to demonstrate the permissible concentration of nickel in the product. If rigorous prevention within 
the next ten years leads to at least a $5 \%$ decrease in the incidence of hypersensitivity to nickel in the Czech population, it will be considered a success.

Measures that could significantly reduce sensitization to Balsam of Peru appear to be less problematic. Since a significant portion of patients is sensitized to Balsam of Peru during therapy of chronic wounds, education of physicians in all fields of specialization should have a positive effect. The situation is eased by the previously mentioned advent of modern dressing into medical practice, which is likely to push medicines containing Balsam of Peru used in these indications into the background.

In the case of the two other important contact allergens, which in our sample represented epoxy resins and chromium, it is necessary to expect sustained exposure of a particular group of people working in a specific field of production. As for the prevention of contact hypersensitivity, it is therefore necessary to focus on the correct job title of each employee and the rigorous observance of hygiene rules, including the wearing of protective gear. In the case of chromium, limitations of chromium in cement according to EU legislation seem to be promising.

Use of a variety of cosmetic products, especially for women, is practically a matter of course, therefore a significant reduction in sensitization to fragrance mix I or Kathon CG can hardly be expected. One of the measures that could alleviate the percentage of sensitized individuals to Kathon CG is the use of preservatives only in products that are rinsed off and not in products that remain on the skin.

ACD will still be one of the most common dermatological diseases. However, the frequency of the disease can, to some extent, be positively affected by objectifying the most common contact allergens in the area and introducing the proper preventive measures. Changes in lifestyle, fashion trends or the introduction of new technologies are some of the factors explaining why the role of individual allergens in the development of ACD may change over time or is regionally different. Similar studies with a sufficiently representative sample of patients should therefore be carried out again at certain time periods. Given that the patch test is a simple, non-invasive and economically feasible method, similar studies can be carried out without major difficulties.

\section{ACKNOWLEGMENT}

We thank to Dr. Jana Zapletalova for statistical analysis.

Author contributions: MT: study design and manuscript writing; IK: data collection, data analysis and literature search.

Conflict of interest statement: The authors state that there are no conflicts of interest regarding the publication of this article.

\section{REFERENCES}

1. Rietschel RL, Fowler JF jr. Fisher's Contact Dermatitis, 5th ed Philadelphia: Lippincott Williams§Wilkins;2001.

2. Machovcova A, Dastychova E, Kostalova D, Vojtechovska A, Reslova J, Smejkalova D, Vaneckova J, Vocilkova A. Common contact sensitizers in Czech Republic. Patch test results in 12058 patients with suspected contact dermatitis. Contact Dermatitis 2005;53:162-6.

3. Akasya-Hillebrand E, Ozkaya-Bayazit E. Patch test result in 524 patients with suspected contact dermatitis in Turkey. Contact Dermatitis 2002;46:17-23.

4. Dotterud LK, Smith-Sivertsen T. Allergic contact sensitization in the general adult population: a population-based study from Northern Norway. Contact Dermatitis 2007;56:10-5.

5. Carlsen BCh, Menne T, Johansen JD. 20 years of standard patch testing in an eczema population with focus on patients with multiple contact allergies. Contact Dermatitis 2007;57:76-83.

6. Thyssen JP, Linneberg A, Menne T, Johansen JD. The epidemiology of contact Allergy in the general population - prevalence and main findings. Contact Dermatitis 2007;57:287-99.

7. Vocilkova A, Dastychova E, Dobesova J, Horazdovsky J, Kostalova D, Machackova J, Reslova J, Vaneckova J. Analysis of Results of Standard Patch Tests in the Czech Republic. Čes-slov Derm 1995;70(3):125-8.

8. Lazarov A. European Standard Series patch test results from a contact dermatitis clinic in Israel during the 7-year period from 1998 to 2004. Contact Dermatitis 2006;55:73-6.

9. Rui F, Bovenzi M, Prodi A, Fortina AB, Romano I, Corradin MT, Filon FL. Nickel, chromium and cobalt sensitization in a patch test population in north-eastern Italy (1996-2010). Contact Dermatitis 2012;68:2331.

10. Liden C. Legislative and preventive measures related to contact dermatitis. Contact Dermatitis 2001;44:65-9.

11. Thyssen JP. Nickel and cobalt allergy before and after nickel regulation - evaluation of a public health intervention. Contact Dermatitis 2011;65:1-68.

12. Thyssen JP, Johansen JD, Carlsen BC, Menné T. Prevalence of nickel and cobalt allergy among female patients with dermatitis before and after Danish government regulation: a 23-year retrospective study. J Am Acad Dermatol 2009;61:799-805.

13. Schnuch A, Uter W. Decrease in nickel Allergy in Germany and regulatory interventions. Contact Dermatitis 2003;49:107-8.

14. Jankicevic J, Vesic S, Vukicevic, Gajic M, Adamic M, Pavlovic MD. Contact sensitivity in patients with venous leg ulcers in Serbia: comparison with contact dermatitis patients and relationship to ulcer duration. Contact Dermatitis 2008;58:32-6.

15. Necas M, Dastychova E. Contact sensitization in patients with lower extremity dermatitis in the South Moravian region, Czech Republic. Phlebology 2010;25:132-7.

16. Tavadia S, Bianchi J, Dawe RS, Mcevoy M, Wiggins E, Hamill E, Urcelay $M$, Strong AMM, Douglas WS. Allergic contact dermatitis in venous leg ulcer patients. Contact dermatitis 2003;48:261-5.

17. Thyssen JP, Carlsen BC, Menné T, Johansen JD. Trends of contact allergy to fragrance-mix I and Myroxylon pereirae among Danish eczema patients tested between 1985 and 2007. Contact Dermatitis 2008;59:238-44.

18. Dastychova E, Dobesova J, Horazdovsky J, Hromadkova R, Janatova H, Karlova I, Keznikl F, Kostalova D, Kulikova Z, Machovcova A, Makhoul M, Necas M, Nemcova H, Novak M, Novak M, Pospisilova V, Reslova J, Rehor I, Schmiedbergerova R, Stuchlik D, Sich J, Vaicova M, Vaneckova J, Vocilkova A, Vojtechovska A, Zemlickova M. Trends in the development of contact sensitivity to selected additives of pharmaceutical and cosmetic products in the Czech Republic. Cesslov Derm 2013;88:73-8.

19. Fewings J, Menné T. An update of the risk assessment for methylchlorisothiazoline /methylisothiazoline (MCl/MI) with focus on rinse-off product. Contact Dermatitis 1999;41:1-13.

20. Bangsgaard N, Thyssen JP, Menné T, Andersen KE, Mortz ChG, Paulsen E, Sommerlund M, Veien NK, Laurberg G, Kaaber K, Thormann J, Andersen BL, Danielsen A, Avnstorp Ch, Kristensen B, Kristensen O, Vissing $\mathrm{S}$, Nielsen $\mathrm{NH}$, Johansen JD. Contact allergy to epoxy resin: risk occupations and consequences. Contact Dermatitis 2012;67:737 . 
21. Jolanki R, Kanerva L, Estlander T, Tarvainen K, Keskinen H, HenricksEckerman ML. Occupational dermatoses from epoxy resin compounds. Contact dermatitis 1990;23:172-83.

22. Kanerva L, Estlander T, Keskinen $H$, Jolanki R. Occupational allergic airborne contact dermatitis and: 172-183 delayed bronchial asthma from epoxy resin revealed by bronchial provocation test. Eur J Dermatol 2000;10:475-7.
23. Machado S, Silva E, Sanches M, Massa A. Occupational airborne contact dermatitis. Am J Contact Dermat 2003;14:31-2.

24. Gier J, Krautheim A, Uter W, Lessmann H, Schnuch A. Occupational contact allergy in the building trade in Germany: influence of preventive measures and changing exposure. Int Arch Occup Environ Health 2011:84:403-11. 